\title{
Rendezvous biliary recanalization with combined percutaneous transhepatic cholangioscopy and double-balloon endoscopy
}

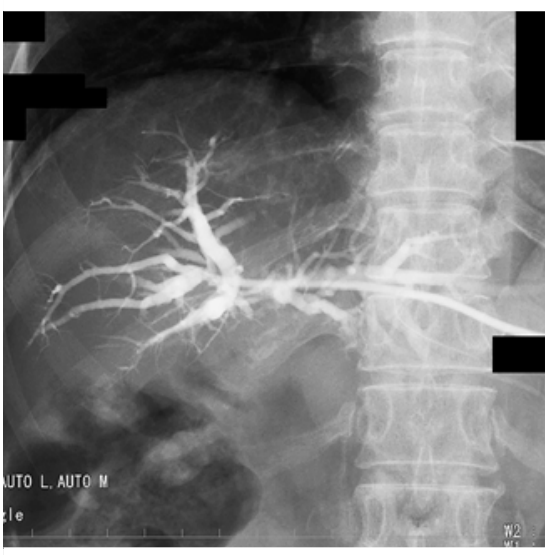

- Fig. 1 Percutaneous transhepatic cholangiogram showing complete obstruction of the choledochojejunal anastomosis in a patient who had undergone pancreaticoduodenectomy 7 years previously.

Despite advances in biliary stenting in patients with altered gastrointestinal anatomy, it is still a challenging procedure [1]. We present a case where percutaneous transhepatic cholangioscopy (PTCS) was combined with double-balloon endoscopy (DBE) for biliary stenting in a patient with complete obstruction of a choledochojejunostomy.

A 71-year-old woman, who had a history of distal cholangiocarcinoma and had undergone pancreaticoduodenectomy 7 years previously, experienced recurrent cholangitis. DBE-assisted balloon dilation had been performed 7 months previously for stricture of the choledochojejunal anastomosis. However, she developed complete obstruction of the anastomosis ( Fig.1). A 7.2-Fr percutaneous transhepatic biliary drainage (PTBD) catheter was initially placed, and the fistula tract was dilated up to $12 \mathrm{Fr}$ within 4 weeks. DBE-assisted endoscopic retrograde cholangiopancreatography was then attempted. First, the double-balloon endoscope (El-580BT; Fujifilm, Tokyo, Japan) was advanced to the afferent limb, and a percutaneous transhepatic cholangiogram revealed complete obstruction of
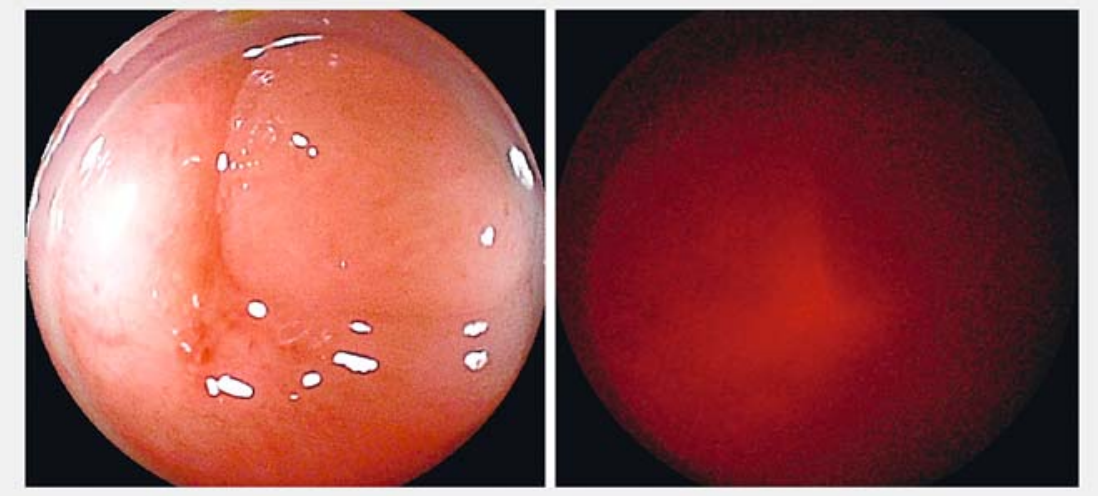

- Fig. 2 Left panel: The choledochojejunal anastomosis has an appearance similar to an ulcer scar. Right panel: Transillumination from the percutaneous transhepatic cholangioscope guides direct precutting using the double-balloon endoscope.
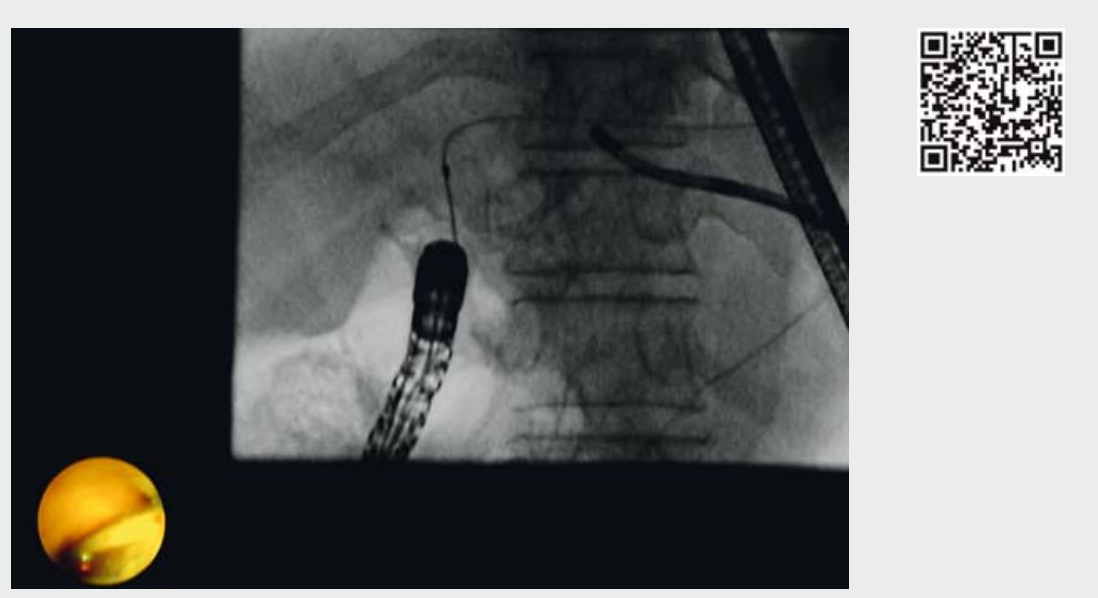

$\nabla$ Video 1 Biliary recanalization, using a rendezvous technique with combined percutaneous transhepatic cholangioscopy and double-balloon endoscopy, for a completely obstructed choledochojejunostomy.

the anastomosis. Next, a PTCS scope (BF type P260F; Olympus, Tokyo, Japan) was inserted via the PTBD route. However, a guidewire (0.018-inch, Pathfinder Exchange; Boston Scientific Japan, Tokyo, Japan) through the PTCS scope could not pass the anastomosis ( Video 1 ). Therefore, we attempted direct precutting (KD-V451M; Olympus) at the anas- tomosis, using the double-balloon endoscope and guided by transillumination from the percutaneous transhepatic cholangioscope' ( Fig. 2, \ Video 1). A small incision was carefully made in order to create a fistula ( $\triangleright$ Fig. $\mathbf{3}$ ). This was followed by successful passage of the guidewire (0.032-inch, Radifocus Guidewire M; Terumo, Tokyo, Japan) 


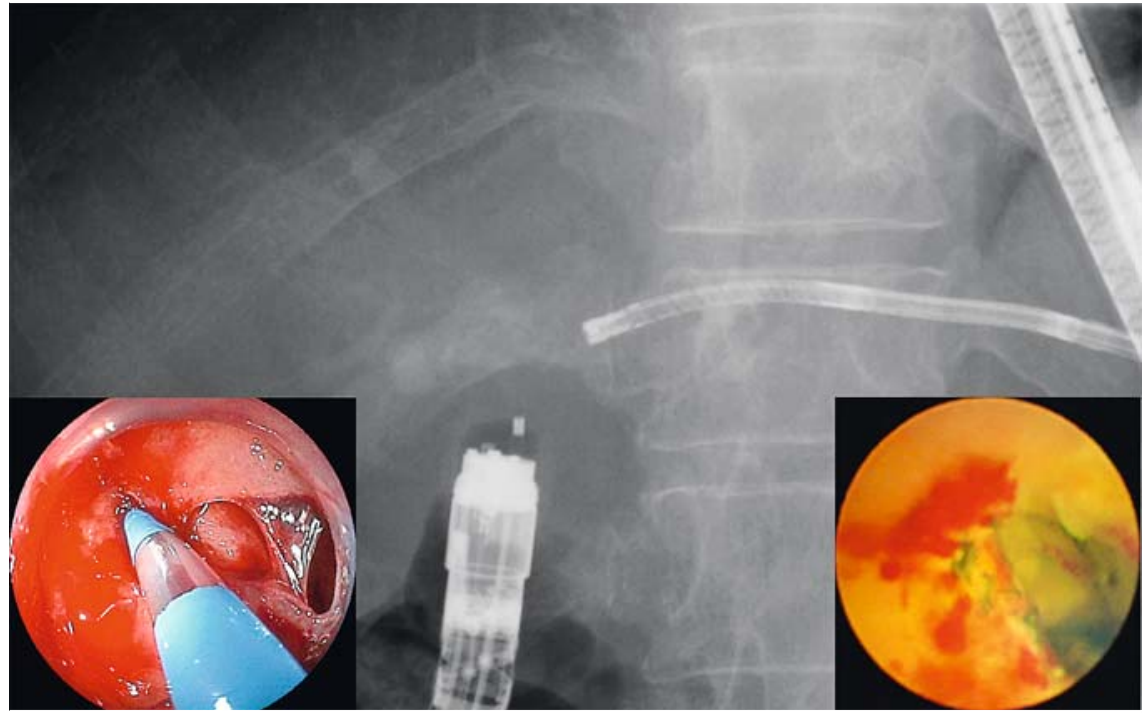

- Fig. 3 Radiograph showing direct precutting at the choledochojejunal anastomosis, under fluoroscopic guidance and transillumination from the percutaneous transhepatic cholangioscope. Left inset: enteroscopy view. Right inset: percutaneous transhepatic cholangioscopy view.

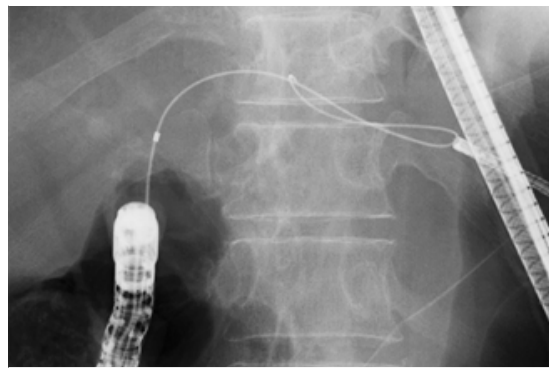

Fig. 5 The guidewire is grasped by means of a snare under fluoroscopic and percutaneous transhepatic cholangioscopic guidance.

completely through the anastomotic obstruction ( $\vee$ Fig. 4 , $>$ Video 1 ). We then grasped the guidewire with an ultraslim basket catheter (Zero Tip Retrieval Basket; Boston Scientific) using the cholangioscope ( $\bullet$ Fig. $5, \triangleright$ Video 1$)$. Finally, a 12-Fr PTBD catheter was placed across the obstruction without any complications ( $\bullet$ Fig. $\mathbf{6}, \triangleright$ Video 1 ).

The rendezvous technique in combination with PTCS and DBE facilitates biliary recanalization of complete biliary obstruction $[1,2]$. However, blind incision has the risk of gastrointestinal tract per-

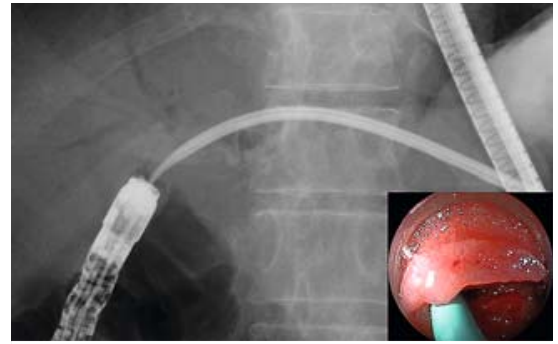

- Fig. 6 Insertion of the percutaneous transhepatic biliary drainage catheter, using a rendezvous technique, across the previously obstructed choledochojejunal anastomosis. Inset: percutaneous transhepatic cholangioscopic view.

foration or bile leakage. Although caution should be exercised, incision guided by transillumination from the peroral transhepatic cholangioscope is a safe and less invasive technique compared with surgery.

Endoscopy_UCTN_Code_TTT_1AR_2AJ

\section{Competing interests}

None

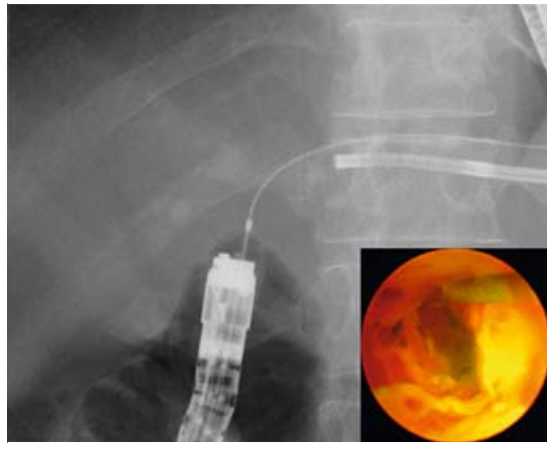

- Fig. 4 Radiograph showing the guidewire passing through the obstruction. Inset: percutaneous transhepatic cholangioscopy view.
The authors

Hiroshi Kawakami ${ }^{1,2}$, Tesshin Ban ${ }^{1,2}$, Yoshimasa Kubota ${ }^{1,2}$, Shinya Ashizuka ${ }^{2}$, Ichiro Sannomiya ${ }^{2}$, Naoya Imamura ${ }^{2,3}$, Takeomi Hamada ${ }^{2,3}$

1 Department of Gastroenterology and Hepatology, Faculty of Medicine, University of Miyazaki, Miyazaki, Japan

2 Department of Gastroenterology and Hepatology, Center for Digestive Disease and Division of Endoscopy, University of Miyazaki Hospital, Miyazaki, Japan

3 Division of Hepato-Biliary-Pancreas Surgery, Department of Surgery, Faculty of Medicine, University of Miyazaki, Miyazaki, Japan 


\section{Hiroshi Kawakami, MD, PhD}

Department of Gastroenterology and Hepatology, Center for Digestive Disease and Division of Endoscopy, University of Miyazaki Hospital, 5200, Kiyotake, Kihara, Miyazaki 889-1692, Japan

Fax: +81-985-859802

hiropon@med.miyazaki-u.ac.jp

\section{References}

[1] Shimatani M, Takaoka M, Ikeura T et al. Rendezvous technique: double-balloon endoscopy and SpyGlass direct visualization system in a patient with severe stenosis of a choledochojejunal anastomosis. Endoscopy 2014; 46 (Suppl. 01): E275 - E276

[2] Bukhari MA, Haito-Chavez Y, Ngamruengphong $S$ et al. Rendezvous biliary recanalization of complete biliary obstruction with direct peroral and percutaneous transhepatic cholangioscopy. Gastroenterology 2018: $154: 23-25$

Bibliography

DOI https://doi.org/10.1055/a-0591-2109

Published online: 13.4.2018

Endoscopy 2018; 50: E146-E148

(c) Georg Thieme Verlag KG

Stuttgart · New York

ISSN 0013-726X

\section{ENDOSCOPY E-VIDEOS}

https://eref.thieme.de/e-videos

回局 Endoscopy E-Videos is a free access online section, reporting 田: on interesting cases and new techniques in gastroenterological endoscopy. All papers include a high quality video and all contributions are freely accessible online.

This section has its own submission website at

https://mc.manuscriptcentral.com/e-videos 